\title{
Diffusion Weighted Magnetic Resonance Imaging in Differentiation of Benign and Malignant Thyroid Nodules
}

\author{
MAHA A. EL-SHINNAWY, M.D.*; MONA A.M. ALI NAGI, M.D.* and SHERIF A. EBRAHIM, M.Sc.** \\ The Department of Radio-Diagnosis, Faculty of Medicine, Ain Shams University* and General Naval Military Hospital**
}

\begin{abstract}
Background: Thyroid nodules are common; their clinical significance is mainly related to excluding malignancy. Regardless of the careful reporting of FNAC and frozen section biopsies, there is significant number of discordance with final histopathology reports, which leads to unnecessary thyroidectomies. DWI-MRI can help in the differentiation of benign and malignant thyroid nodules providing qualitative and quantitative information about the diffusion properties.
\end{abstract}

Aim of Study: Is to determine the diagnostic accuracy of Diffusion-Weighted Imaging (DWI) and Apparent Diffusion Coefficient (ADC) mapping in differentiating benign from malignant thyroid nodules by taking histopathology as the gold standard.

Patients and Methods: This study was performed on 32 cases who were diagnosed by ultrasonography to have thyroid nodules; in the General Naval Military Hospital. The patients were referred from the Surgery Department to the Radiology Department over a period of 18 months (January 2018-June 2018).

Results: In this study the sensitivity of DWI and ADC mapping in differentiating benign from malignant thyroid nodules reached $100 \%$.

Conclusion: Quantitative DWI has a high sensitivity, and may be a reliable, non-invasive and non-radiative imaging modality for the detection of thyroid nodules. ADC values seem to be able to differentiate benign from malignant thyroid disease.

Key Words: DWI-ADC mapping - Thyroid nodules.

\section{Introduction}

THYROID nodules, the most common pathology involving the thyroid gland, consist of discrete lesions within the thyroid gland that are often palpable and typically sonographically distinct from the surrounding thyroid parenchyma. Approx-

Correspondence to: Dr. Maha A. El-Shinnawy, The Department of Radio-Diagnosis, Faculty of Medicine,

Ain Shams University imately $5 \%$ of detected nodules are diagnosed as malignancies, a number that has more than doubled over the past 30 years [1]. These nodules must be distinguished from benign thyroid nodules to correctly and efficaciously treat patients suffering from this pathology.

Because clinical findings do not provide a definitive diagnosis, several useful, non-invasive imaging tests such as Ultrasonography (US) and radionuclide scintigraphy can be used to determine which nodules should be histopathologically evaluated to rule out the possibility of thyroid malignancy. US has been used as a first step in the assessment of these nodules, but no single US criterion has been demonstrated to accurately differentiate benign nodules from malignant nodules. Furthermore, the hazards associated with radiation exposure during radionuclide scintigraphy are unavoidable, and some functioning nodules (hot nodules) found on scintigraphy are malignant [2].

Fine Needle Aspiration Biopsy (FNAB) is regarded as the standard reference for diagnosis, but it has been reported before that FNAB results may mimic some other diseases [3].

Routine T1-and T2-weighted MR imaging cannot differentiate benign from malignant nodules or assess the functional status of thyroid nodules, thus, its role in thyroid nodules evaluation is limited [4].

Diffusion Weighted MRI Imaging (DWI) is an emerging technique for brain tumours. DWI is sensitive to changes in the microstructural organization of tissue that may affect water diffusion. It has been used to evaluate head and neck tumours. The Apparent Diffusion Coefficient (ADC) value is a quantitative parameter for distinguishing malignant from benign thyroid nodules [5]. 
Many studies have shown that DWI has the potential to differentiate benign from malignant thyroid nodules. However, the sample sizes of these studies were relatively small, and the findings have been inconclusive [2].

Aim of the work:

The purpose of our study is to determine the diagnostic accuracy of Diffusion-Weighted Imaging (DWI) and Apparent Diffusion Coefficient (ADC) mapping in differentiating benign from malignant thyroid nodules by taking histopathology as the gold standard.

\section{Patients and Methods}

\section{Patients:}

This study was performed on 32 cases who were diagnosed by ultrasonography to have thyroid nodules.

The study was conducted in the General Naval Military Hospital Radiology Department. The patients were referred from the Surgery Department to the Radiology Department over a period of 18 months (January 2018-June 2019).

The patients' age ranged from 22 to 66 years (median 47); 19 patients were females and 13 were males.

\section{Exclusion criteria:}

Patients known to have contraindications to MRI (pacemaker, metallic foreign body in the eye, cochlear implant, cerebral aneurysm clips, claustrophobia).

\section{Methods:}

All cases were subjected to the following:

- Complete history taking.

- Full clinical examination.

- MR imaging examination.

The study was conducted at the Department of Radiology of the General Naval Hospital with 1.5T scanner unit (Toshiba, New Titan, the Japan) using a neurovascular neck coil. Our standard MR imaging protocol for nodule assessment consisted of the following pulse sequences:

1- T1-weighted and T2-weighted images with no contrast in the axial plane.

2- DWI was performed with axial thyroid gland imaging sequence.

3- ADC maps were generated with the system software by using b-value of $1000 \mathrm{~s} / \mathrm{mm}^{2}$ and obtaining an average value for the three directions of diffusion sensitization.

4- Image analysis: Thyroid nodules were identified on T1-weighted and T2-weighted images, inspected for restricted diffusion on DWI images and ADC value of selected ROI placed in the centre of solid nodules or in solid parts of complex nodules was calculated.

5- Results were revised by more than one expert radiologist.

All cases underwent histopathologic examination and results were correlated with imaging findings.

Data management \& statistical analysis:

- Data collected were revised, coded, tabulated and fed to the computer and analyzed using IBM SPSS software package version 20.0. (Armonk, NY: IBM Corp) Qualitative data were described using number and percent. The KolmogorovSmirnov test was used to verify the normality of distribution Quantitative data were described using range (minimum and maximum), mean, standard deviation, median and Interquartile Range (IQR). Significance of the obtained results was judged at the $5 \%$ level.

- The used tests were:

1- Chi-square test: For categorical variables, to compare between different groups.

2- Monte Carlo correction: Correction for chisquare when more than $20 \%$ of the cells have expected count less than 5 .

3-Student t-test: For normally distributed quantitative variables, to compare between two studied groups.

4- F-test (ANOVA): For normally distributed quantitative variables, to compare between more than two groups, and Post Hoc test (Tukey) for pairwise comparisons.

5- Receiver Operating Characteristic curve $(R O C)$ : It is generated by plotting sensitivity (TP) on $\mathrm{Y}$ axis versus 1-specificity (FP) on $\mathrm{X}$ axis at different cut off values. The area under the ROC curve denotes the diagnostic performance of the test. Area more than $50 \%$ gives acceptable performance and area about $100 \%$ is the best performance for the test. The ROC curve allows also a comparison of performance between two tests.

6- Sensitivity: The capacity of the test to correctly identify diseased individuals in a population "true positives". The greater the sensitivity, the 
smaller the number of unidentified case "false negatives".

7- Specificity: The capacity of the test to correctly exclude individuals who are free of the disease "true negatives". The greater the specificity, the fewer "false positives" will be included.

8- Positive Predictive Value (PPV): The probability of the disease being present among those with positive diagnostic test results.

9- Negative Predictive Value (NPV): The probability that the disease was absent, among those whose diagnostic test results were negative.

\section{Results}

This study included 32 patients with 32 thyroid nodules. They were 19 females $(59.4 \%)$ and 13 males $(59.4 \%)$. Their ages ranged from 22 to 66 years (Table 6). The size of nodules ranged from $13 \mathrm{~mm}$ to $55 \mathrm{~mm}$ in largest diameter with mean of $28.15 \mathrm{~mm}$ (Table 2). Fourteen nodules were located in the left lobe of thyroid gland, seventeen nodules were in the right lobe and one lesion was in thyroid isthmus (Table 3).

All cases underwent MRI examination and Thyroid nodules were identified and inspected for restricted diffusion on DWI images and ADC value of selected ROI placed in the centre of solid nodules or in solid parts of complex nodules was calculated.

$\mathrm{ADC}$ values of the benign thyroid nodules were between 1.0 and $3.0 \times 10^{-3} \mathrm{~mm}^{2} / \mathrm{s}$ (mean: 1.86 , SD: 0.50). ADC values of the malignant thyroid nodules were between 0.3 and $1.0 \times 10^{-3} \mathrm{~mm} / \mathrm{s}$ (mean: 0.78, SD: 0.23).

23 nodules were found to be benign by DWI and ${ }_{-3} \mathrm{ADC}$ mapping with $\mathrm{ADC}$ values above $1.0 \mathrm{X}$ $10^{-3} \mathrm{~mm} / \mathrm{s}$.

6 nodules were found to be malignant by DWI and ${ }_{-3} \mathrm{ADC}$ mapping with $\mathrm{ADC}$ values below $1.0 \mathrm{X}$ $10^{-3} \mathrm{~mm} / \mathrm{s}$.

ADC value was $1.0 \times 10^{-3} \mathrm{~mm}^{2} / \mathrm{s}$ for 3 nodules; two of which were malignant and one was benign according to histopathological results (area of overlap).

All cases underwent histo-pathologic examination; 9 by only FNAC, 3 by FNAC and postsurgical Histopathological examination and 20 by only postsurgical histopathological examination, findings confirmed that there were 24 benign nodules $(75 \%)$ and 8 malignant nodules $(25 \%)$ respectively (Table 4).
Histo-pathologic examination findings were correlated with DWI results and ADC values calculated by Magnetic Resonance Imaging (MRI) (Table 5).

\section{- ROC analysis:}

Furthermore, a Receiver Operator Characteristic (ROC) curve was computed for the ADC values obtained from DWI scans using $b=1000 \mathrm{~s} /$ mm Fig. (1).

The results of the present study are demonstrated in the following tables and figures.

Table (1) showed no statistical difference regarding ages or sexes of studied patients ( $p$-value $>0.05$ ). Independent of malignancy, thyroid lesions occurred more frequently in females than in males.

Tables $(2,3)$ showed no statistical difference regarding size or location of the studied nodules ( $p$-value >0.05).

Table (4) showed that FNAC and/or permanent postsurgical histopathologic examinations of the nodules were as follow: Six papillary carcinomas and two follicular carcinomas, and of benign nodules were as follow: Eleven colloid nodules, six adenomatous nodules, five follicular adenoma and two Hurthle cell adenomas. The definitive diagnosis of cases with carcinoma was confirmed with histopathological examination of postsurgical specimens.

Table (5) showed statistical significant differences between mean ADC values of benign and malignant solitary thyroid nodules ( $p$-value $<0.001)$.

$\mathrm{ADC}$ values of the benign thyroid nodules were between 1.0 and $3.0 \times 10^{-3} \mathrm{~mm} / \mathrm{s}$ (mean: 1.86 , SD: 0.50). ADC values of the malignant thyroid nodules were between 0.3 and $1.0 \times 10^{-3} \mathrm{~mm}^{2} / \mathrm{s}$ (mean: 0.78, SD: 0.23).

23 nodules were found to be benign by DWI and $\mathrm{ADC}$ mapping with $\mathrm{ADC}$ values above $1.0 \mathrm{X}$ $10^{-3} \mathrm{~mm} / \mathrm{s}$.

6 nodules were found to be malignant by DWI and ${ }_{-3} \mathrm{ADC}$ mapping with $\mathrm{ADC}$ values below $1.0 \mathrm{X}$ $10^{-3} \mathrm{~mm} / \mathrm{s}$.

ADC value was $1.0 \times 10^{-3} \mathrm{~mm}^{2} / \mathrm{s}$ for 3 nodules; two of which were malignant and one was benign according to histopathological results.

We determined a cut-off point from the ROC curve Fig. (1) that would differentiate benign from 
malignant lesions. The area under the ROC curve was 0.995. When we selected a cut-off ADC value of $1 \times 10^{-3} \mathrm{~mm}^{2} / \mathrm{s}$, sensitivity and specificity were found to be $100 \%$ and $95.83 \%$ respectively (Table 6).

Sensitivity was found to be $100 \%$ as the ADC values of all malignant nodules were between 1.0 and $3.0 \times 10^{-3} \mathrm{~mm}^{2} / \mathrm{s}$ in other words no false positive results for malignancy were detected.

Specificity was found to be $95.83 \%$ as ADC value was $1.0 \times 10^{-3} \mathrm{~mm} / \mathrm{s}$ for one benign nodule according to histopathological results in other words one false negative result for malignancy was found out of 24 benign nodules.

Table (1): Comparison between the benign and malignant nodules according to demographic data.

\begin{tabular}{|c|c|c|c|c|c|c|c|c|}
\hline & \multicolumn{2}{|r|}{$\begin{array}{c}\text { Total } \\
(\mathrm{n}=32)\end{array}$} & \multicolumn{2}{|c|}{$\begin{array}{l}\text { Benign } \\
(\mathrm{n}=24)\end{array}$} & \multicolumn{2}{|c|}{$\begin{array}{l}\text { Malignant } \\
\quad(\mathrm{n}=8)\end{array}$} & \multirow{2}{*}{ Test of sig. } & \multirow{2}{*}{$p$} \\
\hline & No. & $\%$ & No. & $\%$ & No. & $\%$ & & \\
\hline \multicolumn{9}{|l|}{ Sex: } \\
\hline Male & 13 & 40.6 & 9 & 37.5 & 4 & 50.0 & $\chi^{2}=0.389$ & $0.684 *$ \\
\hline Female & 19 & 59.4 & 15 & 62.5 & 4 & 50.0 & & \\
\hline \multicolumn{9}{|l|}{ Age (years): } \\
\hline Min.-max. & & $22.0-66.0$ & & 66.0 & & -62.0 & $t=0.375$ & $0.710 *$ \\
\hline Mean \pm SD. & & $5.31 \pm 11.28$ & & $=10.75$ & & 13.46 & & \\
\hline \multicolumn{9}{|c|}{ Median (IQR) 47.0 (36.0-54.5) 47.50 (38.5-53.0) 43.0 (34.5-56.0) } \\
\hline
\end{tabular}

Table (2): Comparison between the benign and malignant nodules according to size of nodules and their nature.

\begin{tabular}{|c|c|c|c|c|}
\hline $\begin{array}{l}\text { Maximum } \\
\text { diameter (mm) }\end{array}$ & Total $(n=32)$ & Benign $(n=24)$ & Malignant (n=8) & $p$ \\
\hline $\begin{array}{l}\text { Min.-max. } \\
\text { Mean } \pm \text { SD. } \\
\text { Median (IQR) }\end{array}$ & $\begin{array}{l}13.0-55.0 \\
28.16 \pm 10.76 \\
25.0(20.0-35.0)\end{array}$ & $\begin{array}{l}13.0-55.0 \\
28.92 \pm 11.85 \\
27.50(20.0-37.50)\end{array}$ & $\begin{array}{l}18.0-40.0 \\
25.87 \pm 6.58 \\
25.0(22.50-27.0)\end{array}$ & $0.9060 .374 *$ \\
\hline
\end{tabular}

Table (3): Comparison between the benign and malignant nodules according to location of thyroid nodules.
Table (4): Distribution of the studied cases according to histopathological findings.

\begin{tabular}{|c|c|c|c|c|c|c|c|c|c|c|c|}
\hline \multirow{2}{*}{ Site } & \multicolumn{2}{|c|}{$\begin{array}{c}\text { Total } \\
(\mathrm{n}=32)\end{array}$} & \multicolumn{2}{|c|}{$\begin{array}{l}\text { Benign } \\
(\mathrm{n}=24)\end{array}$} & \multicolumn{2}{|c|}{$\begin{array}{c}\text { Malignant } \\
(\mathrm{n}=8)\end{array}$} & \multirow{2}{*}{$x^{2}$} & \multirow{2}{*}{$\mathrm{MC}_{p}$} & \multirow[b]{2}{*}{$\begin{array}{l}\text { Benign } \\
\text { Adenomatous nodule }\end{array}$} & \multirow{2}{*}{$\begin{array}{c}\text { No. } \\
24 \\
6\end{array}$} & \multirow{2}{*}{$\begin{array}{c}\% \\
75.0 \\
18.8\end{array}$} \\
\hline & No. & $\%$ & No. & $\%$ & No. & $\%$ & & & & & \\
\hline RT lobe & 17 & 53.1 & 14 & 58.3 & 3 & 37.5 & 1.755 & $0.558 *$ & Colloid nodule & 11 & 34.4 \\
\hline LT lobe & 14 & 43.8 & 9 & 37.5 & 5 & 62.5 & & & Hurthle cell adenoma & 2 & 6.3 \\
\hline Isthmus & 1 & 3.1 & 1 & 4.2 & 0 & 0.0 & & & Follicular adenoma & 5 & 15.6 \\
\hline $\begin{array}{l}\chi^{2}: \text { Chi sc } \\
p: p \text {-value } \\
*: \text { Statisti }\end{array}$ & $\begin{array}{l}\text { uare } t \\
\text { for co } \\
\text { cally s }\end{array}$ & $\begin{array}{l}\text { est. } \\
\text { mparir } \\
\text { ignific }\end{array}$ & $\begin{array}{l}\mathrm{g} \text { bety } \\
\text { nt at } p\end{array}$ & $\begin{array}{l}\leq e e n \text {th } \\
\leq 0.05 \text {. }\end{array}$ & $\begin{array}{l}\mathrm{C}: \mathrm{M} \\
\text { studi }\end{array}$ & $\begin{array}{l}\text { nte Car } \\
\text { ed grou }\end{array}$ & & & $\begin{array}{l}\text { Papillary carcinoma } \\
\text { Follicular carcinoma }\end{array}$ & $\begin{array}{l}8 \\
6 \\
2\end{array}$ & $\begin{array}{l}25.0 \\
18.8 \\
6.3\end{array}$ \\
\hline
\end{tabular}

Table (5): Comparison between benign and malignant nodules according to DWI results and ADC values of the nodules.

\begin{tabular}{|c|c|c|c|c|c|}
\hline $\begin{array}{l}\text { ADC value } \\
X 10^{-3}\end{array}$ & Total $(n=32)$ & Benign $(n=24)$ & Malignant $(n=8)$ & $t$ & $p$ \\
\hline Min.-max. & $0.30-3.0$ & $1.0-3.0$ & $0.30-1.0$ & 5.927 & $<0.001 *$ \\
\hline Mean \pm SD & $1.59 \pm 0.65$ & $1.86 \pm 0.50$ & $0.78 \pm 0.23$ & & \\
\hline Median (IQR) & $1.65(1.0-2.0)$ & $1.80(1.6-2.1)$ & $0.80(0.7-1.0)$ & & \\
\hline
\end{tabular}

$t$ : Student $t$-test. $\quad p$ : $p$-value for comparing between the studied groups.

*: Statistically significant at $p \leq 0.05$. 
Table (6): Agreement (sensitivity, specificity) for ADC value to diagnose malignant cases.

\begin{tabular}{|c|c|c|c|c|c|c|}
\hline \multirow{2}{*}{ AUC } & \multirow{2}{*}{$p$-value } & 95\% C.I & \multirow{2}{*}{\multicolumn{2}{|c|}{ Cut off Sensitivity }} & \multirow{2}{*}{ Specificity } & \multirow{2}{*}{ PPV } \\
\hline & & L.L U.L & & & & \\
\hline ADC value 0.995 & $50.008 *$ & 0.9781 .00 & $\leq 1.0$ & 100.0 & 95.83 & 88.9100 .0 \\
\hline $\begin{array}{l}\text { L.L : Lower Limit. } \\
\text { UL : Upper Limit. } \\
\text { AUC : Area Under a C } \\
\text { CI : Confidence Inter }\end{array}$ & $\begin{array}{l}\text { urve. } \\
\text { rvals. }\end{array}$ & $\begin{array}{l}\mathrm{NI} \\
*\end{array}$ & $\begin{array}{l}\text { : Positi } \\
\text { : Negat } \\
\text { : Statis }\end{array}$ & $\begin{array}{l}\text { Predictive Va } \\
\text { Predictive V } \\
\text { lly significan }\end{array}$ & $\begin{array}{l}\text { lue. } \\
\text { lue. } \\
\text { at } p \leq 0.05 \text {. }\end{array}$ & \\
\hline
\end{tabular}

Illustrative cases:

Case (1):

Female patient 35 years old complaining of diffuse neck swelling, Ultrasonography and CT of the neck revealed a solitary exophytic left thyroid lobe heterogeneous mainly hypo-echoic nodule, located antero-medially, measuring $2 \times 1.7 \mathrm{~cm}$ in diameters, displaying intra-nodal vascularity, and echogenic shadowing macro-calcifications with subtle cystic changes, DWI MRI showed restricted diffusion Fig. (2) with ADC value of $0.3 \times 10^{-3}$ $\mathrm{mm} / \mathrm{s}$ Fig. (3) and malignant features on histopathological correlation (papillary carcinoma on surgical biopsy and Bethesda score V on FNAC).

\section{Case (2):}

Female patient 47 years old complaining of dysphagia and neck discomfort, Ultrasonography of the neck revealed a left lobe hyper echoic nodule that measured $1.8 \times 1.3 \mathrm{~cm}$ in diameters showingincreased intra-nodal vascularity on color Doppler examination (TI-RADS 3), DWI MRI showed no restricted diffusion Fig. (4) with ADC value of 1.8 $\mathrm{X} 10^{-3} \mathrm{~mm} / \mathrm{s}$ Fig. (5) and benign features on histopathological correlation (Colloid nodule of Bethesda score II on FNAC).

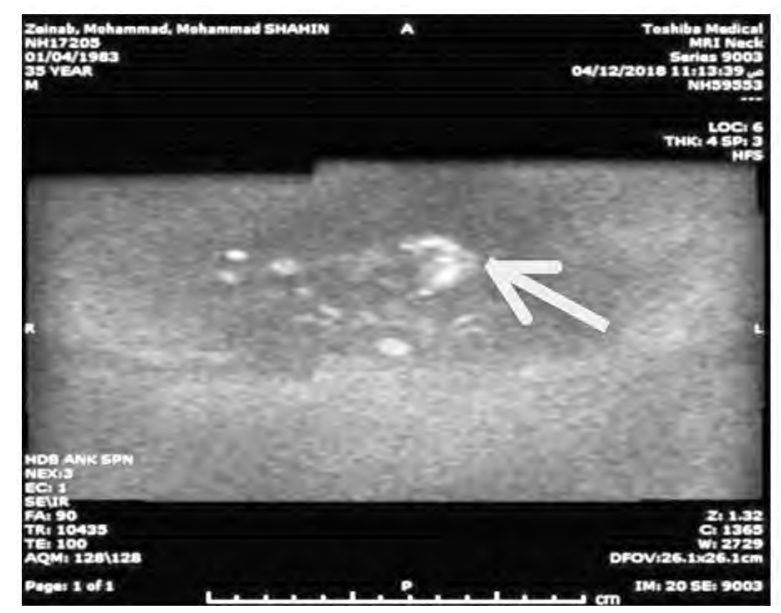

Fig. (2): DWI MRI showed restricted diffusion.

\section{Case (3):}

Male patient 56 years old complaining of neck swelling and dysphagia, Ultrasonography of the neck a left thyroid lobe nodule measuring about $3 \mathrm{~cm}$ in maximum diameter (TI-RADS 4), DWI MRI showed restricted diffusion Fig. (6) with ADC value of $0.8 \times 10^{-3} \mathrm{~mm} / \mathrm{s}$ Fig. (7) and malignant features on histo-pathological correlation (Bethesda score V on FNAC and papillary carcinoma on surgical biopsy).

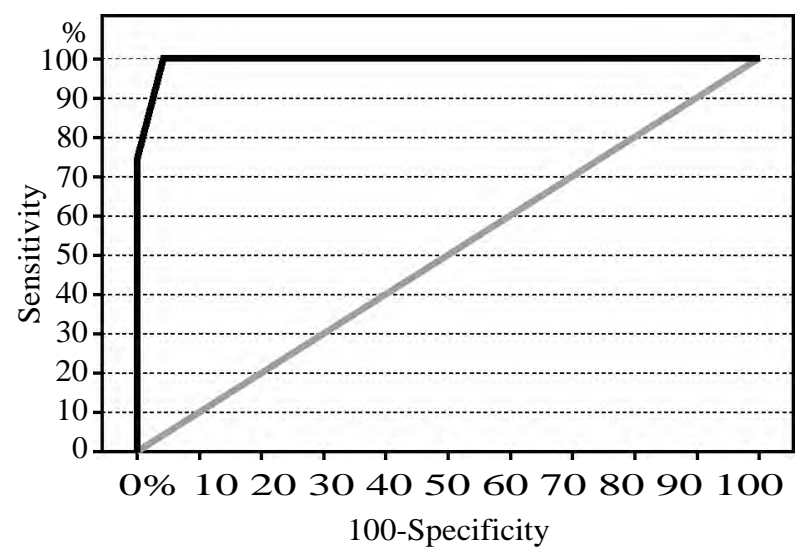

Fig. (1): ROC curve for ADC value to diagnose malignant cases.

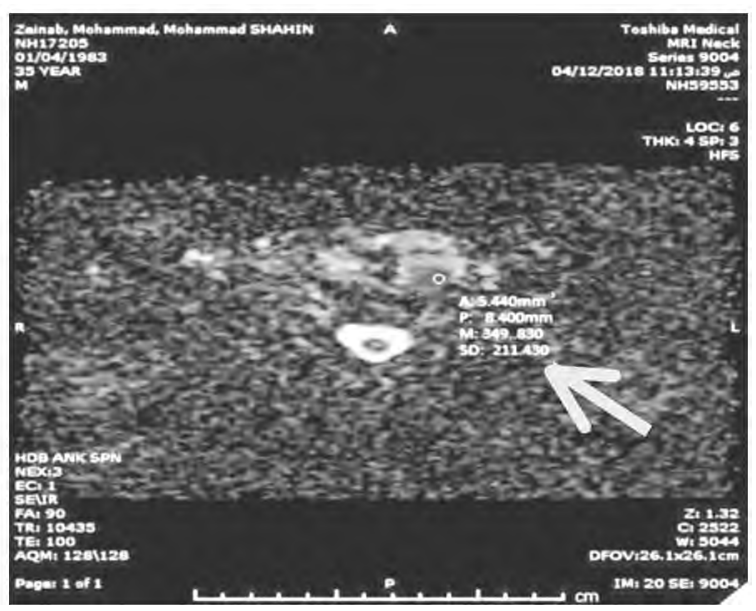

Fig. (3): ADC value of $0.3 \times 10^{-3} \mathrm{~mm}^{2} / \mathrm{s}$. 


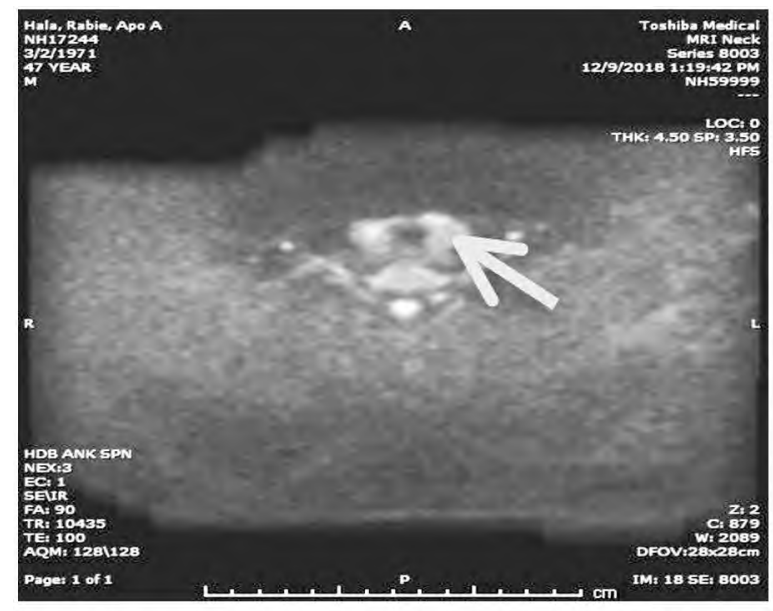

Fig. (4): DWI MRI showed no restricted diffusion.

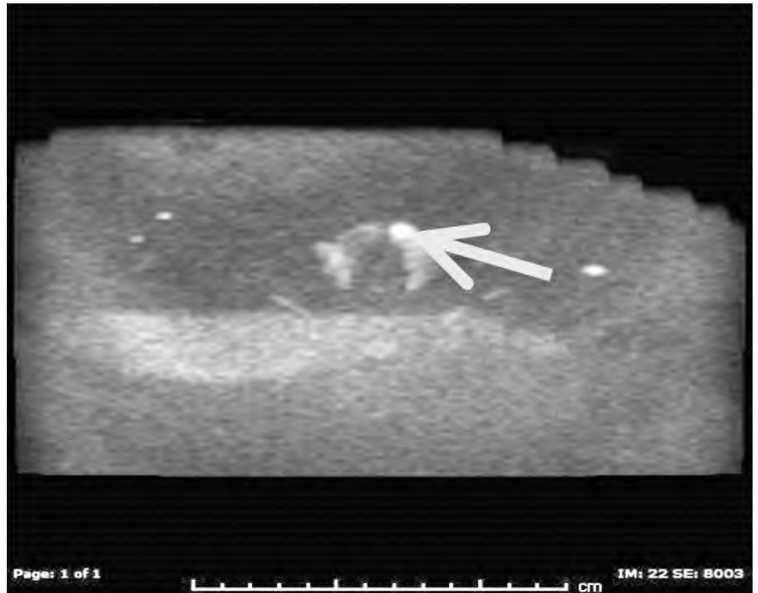

Fig. (6): DWI MRI showed restricted diffusion.

\section{Discussion}

Thyroid nodules are highly prevalent and clinically difficult to manage. Compared with benign thyroid nodules, malignant thyroid nodules have larger nuclei, denser stroma and higher cell counts, all of which lead to increased cellularity and reduced extracellular space [2].

Studies have shown that routine imaging studies lead to high rates of detection of incidental thyroid nodules. With the wide-spread clinical application of sonography, the prevalence of thyroid nodules has increased from $20 \%$ to $67 \%$ in some selected populations. The prevalence of thyroid nodules in patients with no history of thyroid disease was 37$57 \%$ in surveys based on autopsy [1].

Evaluation of thyroid nodules should distinguish benign from malignant nodule aiming for early diagnosis and subsequent earlier treatment and avoiding unneeded surgery in patients with benign nodules [4].

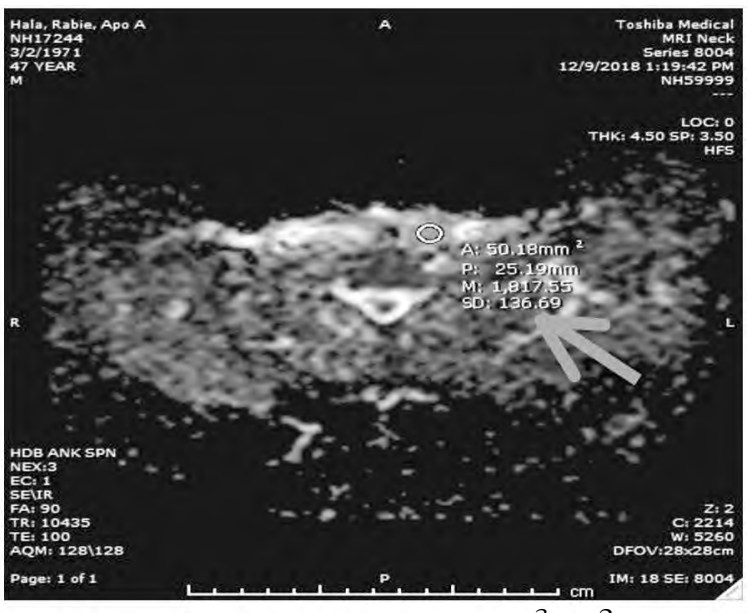

Fig. (5): ADC value of $1.8 \times 10^{-3} \mathrm{~mm}^{2} / \mathrm{s}$.

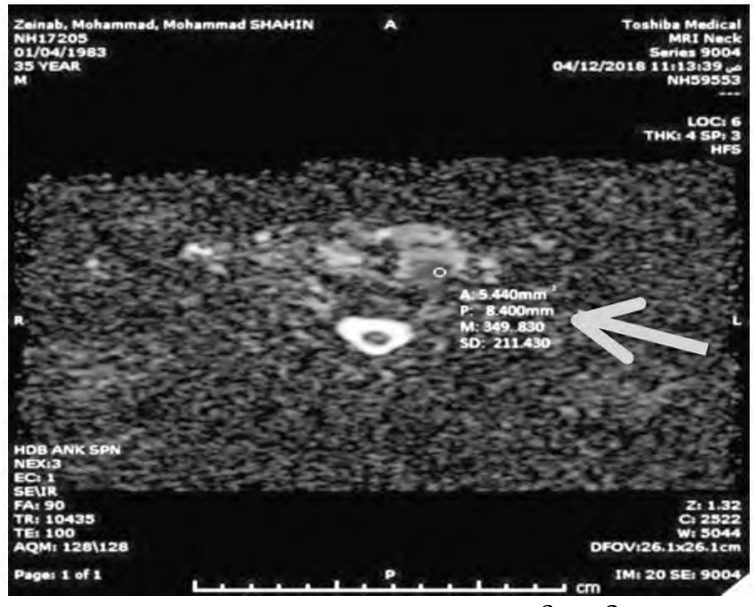

Fig. (7): ADC value of $0.8 \times 10^{-3} \mathrm{~mm}^{2} / \mathrm{s}$

High resolution real time ultrasound is often the first modality used in the diagnostic workup of a thyroid swelling. However, it has limited value in distinguishing benign from malignant lesions [4].

Discrimination of malignant from benign thyroid nodules using FNAB is common and very effective. However, $28 \%$ of patients were found to be inconclusive even with experienced hands. To decrease the risk of unneeded surgery, there is a need for a new non-invasive pre-surgical diagnostic test [4].

Thyroid nodule FNAC is inconclusive in cases of inadequate specimens, indeterminate cytology, sampling errors, risk of hematoma formation, pain and inability to distinguish benign follicular lesions from malignant ones are the most common limitations of FNAC, in those nodules confirmatory results depend on permanent post-surgical histopathological examination results [4]. 
Diffusion weighted imaging is one of the functioning MRI modalities which is used to evaluate thyroid nodules [5].

Diffusion weighted signal is produced from the movement of water in the intra, and extra cellular spaces and also from intravascular spaces. According to degree of cellularity the MRI image appears. The malignant tumors have reduced extracellular spaces with resultant reduction in apparent diffusion coefficient [5].

MRI signal intensity characteristics of thyroid lesions may enable us to differentiate different types of thyroid lesions, potentially improving clinical management. Some studies have evaluated thyroid diseases, including Grave's disease, subacute thyroiditis, and Hashimoto thyroiditis using DWI. DWI might be useful for the diagnosis of thyroid diseases and could be clinically important in the evaluation of thyroid function. A few studies have investigated the differentiation of malignant and benign thyroid nodules using DWI. Generally, the ADC values of the malignant nodules were reported to be significantly lower than those of benign thyroid nodules [1].

Although T1-weighted imaging was not useful in the differentiation of malignant and benign thyroid nodules, T1-weighted imaging in conjunction with $\mathrm{T} 2$-weighted imaging may play a supportive role in detecting haemorrhage or fat within thyroid nodules [1].

It was confirmed that the hyper-cellularity and enlarged nuclei in malignant tumours result in restriction of water diffusion. The increase in cellularity, restriction of intracellular distance, and water diffusion result in low ADC values [4].

Our study included 32 patients with 32 thyroid nodules. They were 19 females $(59.4 \%)$ and 13 males $(59.4 \%)$. Their ages ranged from 22 to 66 years. The size of nodules ranged from $13 \mathrm{~mm}$ to $55 \mathrm{~mm}$ in largest diameter with mean of $28.15 \mathrm{~mm}$. Fourteen nodules were located in the left lobe of thyroid gland, seventeen nodules were in the right lobe and one lesion was in thyroid isthmus.

No statistical difference was noted regarding size of nodule, location of nodule, ages or sexes of studied patients. Independent of malignancy, thyroid lesions occurred more frequently in females than in males in concordance with $[\mathbf{1 , 4 , 5 ]}$.

In our study, DW-MRI was performed on all subjects at $b$-value of $1000 \mathrm{~s} / \mathrm{mm}^{2}$. The mean ADC values of thyroid nodules were measured. In the benign nodules the ADC values of thyroid nodules were between 1.0 and $3.0 \times 10^{-3} \mathrm{~mm} / \mathrm{s}$ (mean: 1.86, SD: 0.50). In the malignant group the ADC values of thyroid nodules were between 0.3 and $1.0 \times 10^{-3} \mathrm{~mm} / \mathrm{s}$ (mean: 0.78, SD: 0.23 ). There is significant difference between ADC value of benign and malignant thyroid nodules $(p>0.001)$.

23 nodules were found to be benign by DWI and ${ }_{-3} \mathrm{ADC}$ mapping with ADC values above $1.0 \mathrm{X}$ $10^{-3} \mathrm{~mm} / \mathrm{s}$ and 6 nodules were found to be malignant by DWI and ADČ mapping with ADC values below $1.0 \times 10^{-3} \mathrm{~mm} / \mathrm{s}$.

ADC value was $1.0 \times 10^{-3} \mathrm{~mm}^{2} / \mathrm{s}$ for 3 nodules; two of which were malignant and one was benign according to histopathological results (area of overlap).

In this study we used the histo-pathological examination results as the gold standard for malignancy.

All nodules underwent histo-pathologic examination, findings confirmed that there were 24 benign nodules $(75 \%)$ and 8 malignant nodules (25\%) respectively.

Histo-pathologic examination findings were correlated with DWI results and ADC values calculated by Magnetic Resonance Imaging (MRI).

ADC value of $1 \times 10^{-3} \mathrm{~mm}^{2} / \mathrm{s}$ was used as a cut-off value from the ROC curve for the differentiation of benign from malignant thyroid nodules, The sensitivity, Specificity, PPV, NPV and $p$-value were $100 \%, 95.83 \%, 88.9 \%, 100 \%$, and $<0.008$ respectively for b-value $1000 \mathrm{~s} / \mathrm{mm}$.

Sensitivity was found to be $100 \%$ as the ADC values of all malignant nodules were between 1.0 and $3.0 \times 10^{-3} \mathrm{~mm} / \mathrm{s}$ in other words no false positive results for malignancy were detected.

Specificity was found to be $95.83 \%$ as ADC value was $1.0 \times 10^{-3} \mathrm{~mm} / \mathrm{s}$ for one benign nodule according to histopathological results in other words one false negative result for malignancy was found out of 24 benign nodules.

Our results were in concordance with Mutlu et al, 2011 study [6] who found in their study that the sensitivity, specificity, PPV, Negative Predictive Value (NPV) and accuracy rates for ADC values in distinguishing between benign and malignant thyroid nodules were calculated as $80 \%, 97 \%$, $80 \%, 97 \%$ and $96 \%$, respectively for $b$-values 50 , 
400 and $1000 \mathrm{~s} / \mathrm{mm}^{2}$ when using the cut-off value of $1.0 \times 10^{-3} \mathrm{~mm} / \mathrm{s}$. Similarly; our results were in agreement with Abdel Razek et al., 2008 study [9], as they used ADC value of $0.98 \times 10 \mathrm{X}$ ${ }^{-3} \mathrm{~mm} / \mathrm{s}$ as an indicator of malignancy, with a sensitivity of $97.5 \%$, a specificity of $91.7 \%$, and an accuracy of $98.9 \%$ for b values 250 and 500 s/ $\mathrm{mm}^{2}$ [4].

Our results were not in agreement with AbdelRahman et al., 2016 study [4] study ${ }_{2}$ which used a higher ADC value of $1.5 \times 10^{-3} \mathrm{~mm} / \mathrm{s}$ as a cut-off value for the differentiation of benign from malignant solitary thyroid nodules. The sensitivity, specificity, PPV, NPV and $p$-value were $100 \%$, $100 \%, 100 \%, 100 \%, 100$ and $<0.001$, respectively for b-value $1000 \mathrm{~s} / \mathrm{mm}^{2}$. Similarly; Nakahira et al., 2012 study [7] found that a higher çut-off value for malignant nodules of $1.60 \times 10^{-3} \mathrm{~mm}^{2} / \mathrm{s}$ yielded sensitivity, specificity, and accuracy of $94.73 \%$, $82.60 \%$, and $88.09 \%$, respectively for b-value 1000 $\mathrm{s} / \mathrm{mm}^{2}$ [4].

On the contrary, in Schueller-Weidekamm et al., study [8], the opposite result was reported likely because it was restricted to cold thyroid nodules on scintigraphy. ADC values were higher in malignant thyroid nodules than that in benign nodules with cut-off value of $2.25 \times 10^{-3} \mathrm{~mm}^{2} / \mathrm{s}$ or higher for differentiation of benign from malignant cold thyroid nodules, with an accuracy of $88 \%$, a sensitivity of $85 \%$, and a specificity of $100 \%$ [4,5].

A meta-analysis that included seven similar studies regarding the potential of DWI to differentiate between malignant and benign thyroid nodules was published in 2014, and suggested that DWI can be used as a diagnostic tool to distinguish benign from malignant thyroid nodules by measuring the ADC. Another one in 2016, eight additional references were included that were not present in the aforementioned meta-analysis. It examined the technical aspects of DWI and its additional value in tumor characterization. The results showed that the pooled weighted sensitivity and specificity of the 15 included studies were 0.90 (95\% CI 0.85 to 0.93 ) and 0.95 (95\% CI 0.88 to 0.98$)$, respectively. These results demonstrated that DWI has a high sensitivity and specificity for differentiating malignant from benign thyroid nodules. This result indicated that DWI is an accurate modality for detecting malignant thyroid lesions [2].

Different studies showed variation in the cutoff values for predicting thyroid carcinoma, so, each MRI unit should determine the exact threshold value for predicting malignancy in thyroid nodules as there are variations in MRI systems, coils and pulse sequence [4].

Our study contains several inherent limitations that should be considered when interpreting our results. First, this was a retrospective study with a relatively small sample size, which might have caused selection bias and is a particular problem in diagnostic studies as it may result in an overestimation of the diagnostic accuracy. Further clinical studies need to be performed to validate our quantitative data. Second, although we carefully avoided cystic portions of thyroid nodules in signal intensity measurements, the micro-cystic structure of thyroid nodules may affect our results. Third, other histologic types, even if rare, should be evaluated in further trials. Finally, follow-up of the cases is difficult as the first line of management nowadays is mostly total surgical thyroidectomy and some studies showed that benign thyroid nodules may include occult thyroid carcinoma [1,2].

\section{Conclusion:}

Quantitative DWI has a high sensitivity and specificity, and may be a reliable, non-invasive and non-radiative imaging modality for the detection of thyroid nodules. ADC values seem to be able to differentiate benign from malignant thyroid disease. So DWI seems to have the potential to be of great value as a diagnostic tool in addition to thyroid sonography and US guided-FNAC for tissue characterization of thyroid nodules, even these results may have a role in the selection of nodules that are going to undergo FNAC. Further studies are needed to determine whether diffusionweighted MR imaging could be added to the routine imaging technique used for differentiating malignant from benign thyroid nodules.

\section{References}

1- NODA Y., KANEMATSU M. GOSHIMA S. KONDO H. WATANABE H. KAWADA H. and BAE K.T.: MRI of the Thyroid for Differential Diagnosis of Benign Thyroid Nodules and Papillary Carcinomas. AJR, 204: W332W335, 2015.

2- CHEN L., XU J., BAO J., HUANG X., HU X., XIA Y. and WANG J.: Diffusion-weighted MRI in differentiating malignant from benign thyroid nodules: A meta-analysis. BMJ Open, 6: e008413, 2016.

3- WU Y., YUE X., SHEN W., DU Y., YUAN Y., TAO X. and TANG C.Y.: Diagnostic value of diffusion-weighted MR imaging in thyroid disease: Application in differentiating benign from malignant disease. BMC Medical Imaging, 13: 23, 2013. 
4- ABDEL-RAHMAN H.M., ABOWARDA M.H. and ABDEL-AAL S.M.: Diffusion-weighted MRI and apparent diffusion coefficient in differentiation of benign from malignant solitary thyroid nodule. The Egyptian Journal of Radiology and Nuclear Medicine, 45: 1385-90, 2016.

5- ABD EL AZIZ L.A., HAMISA M. and BADWY M.E.: Differentiation of thyroid nodules using diffusion-weighted MRI. Alexandria Journal of Medicine, 51: 305-9, 2015.

6- MUTLU H., SIVRIOGLU A. and SONMEZ G.: Role of apparent diffusion coefficient values and diffusionweighted magnetic resonance imaging in differentiation between bengin and malignant thyroid nodules. Clin. Imag., 36 (1): 1-7, 2011.

7- NAKAHIRA M., SAITO N. and MURATA S.I.: Quanti- tative diffusion-weighted magnetic resonance imaging as a powerful adjunct to fine needle aspiration cytology for assessment of thyroid nodules. Am. J. Otolaryngol., 33 (4): 408-16, 2012.

8- SCHUELLER-WEIDEKAMM C., KASERER K., SCHUELLER G., SCHEUBA C., RINGL H. and WEBER M.: Can quantitative diffusion-weighted MR imaging differentiate benign and malignant cold thyroid nodules? Initial results in 25 patients. AJNR Am. J. Neuroradiol., 30: 41722, 2009.

9- ABDEL RAZEK A.A.K., SADEK A.G., KOMBAR O.R., ELMAHDY T.E. and NADA N.: Role of apparent diffusion coefficient values in differentiation between malignant and benign solitary thyroid nodules. AJNR Am. J. Neuroradiol., 29: 563-8, 2008.

\section{دور الرنين المغناطيسى الموزن بمعامل الإنتشار

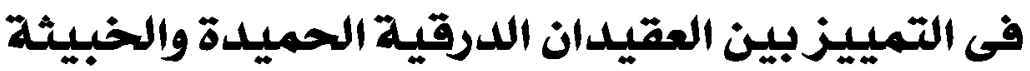

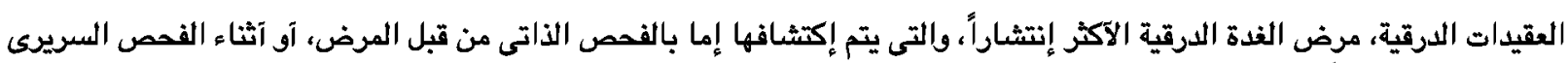

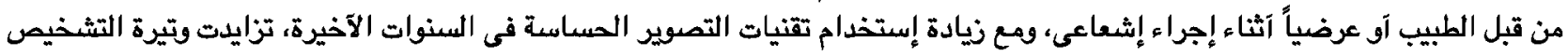

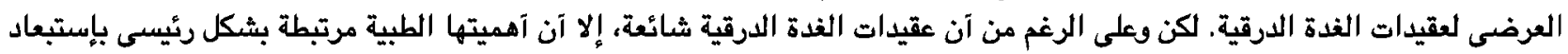
كونها خبيثة.

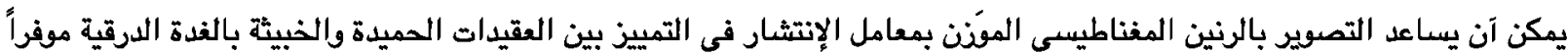

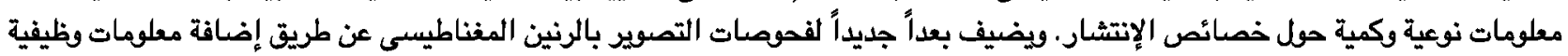

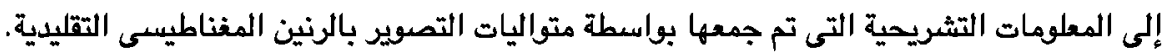

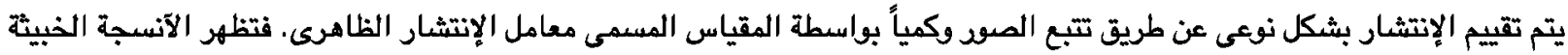

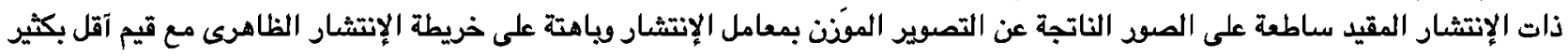
من تلك الموجودة فى العقيدات الدرقية الحميدة.

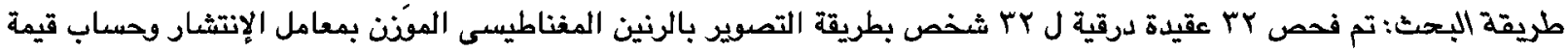

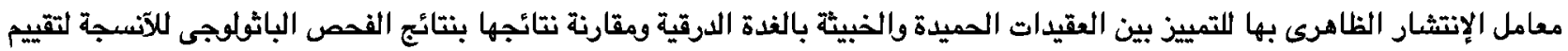
مدى كفائتها فى التمييز بين العقيدات الحميدة والخبيثة بالغدة الدرقية.

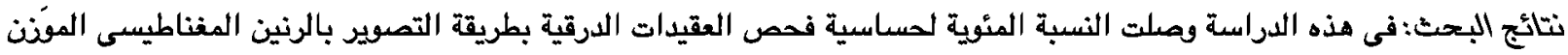

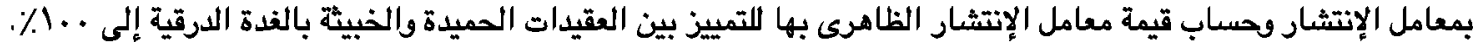

